Pawel Gromek - Rafal Wrobel

\title{
RISK ASSESSMENT IN ROAD TRANSPORT. OPERATIONAL PERSPECTIVE OF THE FIRE SERVICE IN POLAND
}

The paper presents a fire service determined picture of road safety in Poland in its operational (non-system and system) dimensions. It focuses on the road risk assessment, using data related to interventions conducted in 2015-2019 by entities of the State Firefighting Rescue System. The database of the Main Headquarters of the State Fire Service in Poland is adopted and 661,775 emergency road interventions are taken into account.

The results state general framework for procedures, resource allocation and training for fire services. The framework is determined by the riskiest kinds of events on the Polish roads. It refers to micro scale (in relation to operational procedures, tactics and strategies, allocation of equipment and training programs) and macro scale (regarding to emergency system, central-planned equipment procurements and training framework).

Keywords: risk, risk assessment, road, transport, fire service, safety, security

\section{Introduction}

Road transport plays a significant role in every modern society [1]. Consequently, the road safety inscribes to fundamental issues of human operation that is emphasized at national and European levels [2-5]. Notably, that summary value of road collisions and accidents consequences can exceed total consequence value of disasters (floods, hurricanes, wildfires, etc.) [6].

Researchers have been analyzing the road safety phenomena for many years. The studies cover different and partially referenced problematic aspects, which concern (i.a.) statistics of accidents [5], risk factors and risk assessment [7-8], subjectivity of passengers' safety [9], emergency service operations in terms of traffic accidents [10], resource scheduling [11] and response simulation [12]. Among many different road safety perspectives, one seems to be especially influential and more cognitively valuable that the others. In addition, it is relatively rarely taken into consideration in the literature. It is an emergency service perspective, which reflects the most important values to be protected (people life and health) in difficult circumstances of direct danger to people life. Focusing on the road collisions and accidents, when emergency services are involved to rescue people, allows to put a special attention on events with the highest influence on safety. It is caused by the events mediumistic and mass influence, as they refer to safety sense of individuals and entire society. More, a distinct possibility to get a new knowledge for practitioners (public administration, public services) is noticed.

From the practitioners' perspective, it is crucial to assess the road safety level in terms of different kinds of vehicles, considering such fundamental organizational issues as procedures, resource allocation and training.
Furthermore, only the real data-based assessment can ensure that the results will state a realistic input for decision makers who manage these issues on the $\mathrm{n}$ micro scale (in relation to operational procedures, tactics and strategies, allocation of equipment and training programs) and macro scale (regarding to emergency system, centralplanned equipment procurements, training framework). As risk is dealt with as the safety measure [13-15], road risk assessment in analyzed context is particularly desired.

This study focuses on the road risk assessment, using data related to interventions conducted in 2015-2019 by entities of the State Firefighting Rescue System (SFRS). The time horizon provides to the most actual data and is related to the current SFRS evaluation. The evaluation regards implementation of lessons-learned collected during 25 years of the system operation and takes into consideration actual operational tendencies (especially the increase of SFRS operational domain regarding the chemical, biological, radiological and nuclear issues; CBRN issues, also related to the road risk) [16-18]. The database of the State Fire Service (SFS) in Poland is adopted and 661,775 emergency road interventions are analyzed. The results are referred to current road safety determinants on the micro and macro scale. Thus, the study presents a fire service determined picture of the road safety in Poland in its operational (nonsystem and system) dimensions.

\section{Methodology}

\subsection{Data source description}

The SFS is a primary firefighting rescue entity in Poland. It states a core of SFRS. The institution organizes

Pawel Gromek*, Rafal Wrobel

The Main School of Fire Service, Warsaw, Poland

*E-mail of corresponding author: pgromek@sgsp.edu.pl 
Table 1 Road events when SFRS entities operated in 2019

\begin{tabular}{|c|c|c|c|c|c|}
\hline \multirow[b]{2}{*}{ Size category for F/LH } & \multicolumn{5}{|c|}{ Category of transportation mean $(j)$} \\
\hline & Sum & $\begin{array}{l}\mathrm{T} 1 \text { - motorcycles, } \\
\text { bikes }\end{array}$ & $\begin{array}{l}\mathrm{T} 2 \text { - buses, } \\
\text { trolley buses }\end{array}$ & $\begin{array}{c}\text { T3 - lorries, heavy traffic } \\
\text { machines, tanks, lorry trailers }\end{array}$ & $\begin{array}{l}\mathrm{T} 4 \text { - cars, light traffic } \\
\text { machines, car trailers }\end{array}$ \\
\hline \multicolumn{6}{|l|}{ F } \\
\hline Small (F/S) & 9843 & 132 & 185 & 1091 & 8306 \\
\hline Medium (F/M) & 65 & 1 & 3 & 25 & 32 \\
\hline $\operatorname{Big}(\mathrm{F} / \mathrm{B})$ & 2 & 0 & 1 & 0 & 0 \\
\hline Very big (F/VB) & 0 & 0 & 0 & 0 & 0 \\
\hline $\operatorname{Sum}(F)$ : & 9910 & 133 & 189 & 1116 & 8338 \\
\hline \multicolumn{6}{|l|}{ LH } \\
\hline Small (LH/S) & 3558 & 204 & 57 & 393 & 2806 \\
\hline Locally limited (LH/L) & 62364 & 2898 & 507 & 4507 & 53942 \\
\hline Medium (LH/M) & 2948 & 50 & 67 & 504 & 2252 \\
\hline Big (LH/B) & 24 & 0 & 8 & 3 & 10 \\
\hline Catastrophic (LH/C) & 0 & 0 & 0 & 0 & 0 \\
\hline Sum (LH): & 68894 & 3152 & 639 & 5407 & 59010 \\
\hline
\end{tabular}

the system and makes the relevant coordination at all the operational levels (intervention, tactical and strategic) [19]. When serious road accident occurs and people life, health, property and environment are in danger, SFRS entities (SFS, voluntary fire services, etc.) are dispatched. The SFS plays there a leading role, having to its disposal a wide spectrum of legal tools and direct access to specialized resources (well-trained staff and equipment).

Respecting to its position in SFRS, the SFS is responsible for the intervention documentation. This task is operationalized by implementation of the decision support system with statistics module (SWD-ST). The system archives all information structurally collected by SFRS commanders at the emergency operation scene. The information statement is accessible from the SFS Main Headquarters website [20].

The structure of the database considers a causes-based division of all the accidents, respecting two fundamental (from fire services point of view) kinds of negativelyperceived events - fires (F) and local hazards (LH).

Fire formally means uncontrolled combustion process in undesirable place. As far as events documentation is concerned, fires are divided into four categories [19, 21]:

- Small Fire (F/S) characterized by burning area of $70 \mathrm{~m}^{2}$ or volume of $350 \mathrm{~m}^{3}$ or forests, fields, peat bogs and wasteland at area lower than 1 ha or events which require maximum 4 extinguishing jets;

- Medium Fire (F/M) characterized by burning area from $71 \mathrm{~m}^{2}$ to $300 \mathrm{~m}^{2}$ or volume of $351 \mathrm{~m}^{3}$ to $1500 \mathrm{~m}^{3}$ or forests, fields, peat bogs and wasteland at area from 1 ha to 10 ha or events which require from 5 to 12 extinguishing jets;

- Big Fire $(\mathrm{F} / \mathrm{B})$ characterized by burning area from $301 \mathrm{~m}^{2}$ to $1000 \mathrm{~m}^{2}$ or volume of $1501 \mathrm{~m}^{3}$ to $5000 \mathrm{~m}^{3}$ or forests, fields, peat bogs and wasteland at area from
10 ha to 100 ha or events which require from 13 to 36 extinguishing jets;

- Very Big Fire (F/VB) characterized by parameters that exceed values for $\mathrm{F} / \mathrm{B}$.

Local hazard $(\mathrm{LH})$ is understood as any kind of negative phenomena that is not fire - event, which states danger to people, property or environment and is a consequence of civilization development, people operation or natural disaster. LH categories are compiled below:

- Small Local Hazard (LH/S) related to scope-limited events, conducting without the use of specialized equipment (except measurement instruments, which identify no agents);

- Locally-limited Local Hazard (LH/L) corresponding to urgent failures of machines, instruments, vehicles and other object, when maximum 1 victim is dead or maximum 3 victims are supported by medical rescue teams (from outside the SFRS) or maximum 4 fire service teams (12-24 firefighters) participate in the action;

- Medium Local Hazard (LH/M) corresponding to urgent failures of machines, instruments, vehicles and other object, when 2-3 victims are dead or 4-10 victims are supported by medical rescue teams (from outside SFRS) or maximum 5-12 fire service teams (15-72 firefighters) participate in the action or 1 special rescue unit supports the primary rescue resources;

- Big Local Hazard (LH/B), that means urgent, unforeseen event, which refers to mass danger to people life, health, property or environment, exceeds quantitative values of $\mathrm{LH} / \mathrm{M}$ and requires the SFRS resources in strength of 1 battalion (to 480 firefighters);

- Catastrophic Local Hazard (LH/C) related to urgent, unforeseen event, which refers to mass danger to people life, health, property or environment and 
Table 2 Detailed equations for elementary road risk assessment

\begin{tabular}{|c|c|c|c|c|c|}
\hline \multirow[b]{2}{*}{$\mathrm{C}_{\mathrm{i}}$} & \multirow{2}{*}{$\begin{array}{c}\text { Class of } \\
\text { consequences (i) }\end{array}$} & \multicolumn{4}{|c|}{ Category of transportation mean (j) } \\
\hline & & $\begin{array}{l}\mathrm{T} 1 \text { - motorcycles, } \\
\text { bikes }\end{array}$ & $\begin{array}{c}\text { T2 - buses, trolley } \\
\text { buses }\end{array}$ & $\begin{array}{l}\text { T3 - lorries, heavy traffic } \\
\text { machines, tanks, lorry trailers }\end{array}$ & $\begin{array}{l}\mathrm{T} 4 \text { - cars, light traffic } \\
\text { machines, car trailer }\end{array}$ \\
\hline 1 & $\mathrm{~F} / \mathrm{S}$ & $\mathrm{R}_{\mathrm{F} / \mathrm{S}, \mathrm{T1}}=\mathrm{P}_{\mathrm{F} / \mathrm{S}, \mathrm{T1}} \cdot 1$ & $\mathrm{R}_{\mathrm{F} / \mathrm{T}, \mathrm{T2}}=\mathrm{P}_{\mathrm{F} / \mathrm{S}, \mathrm{T2}} \cdot 1$ & $\mathrm{R}_{\mathrm{F} / \mathrm{S}, \mathrm{T3}}=\mathrm{P}_{\mathrm{F} / \mathrm{S}, \mathrm{T3}} \cdot 1$ & $\mathrm{R}_{\mathrm{F} / \mathrm{T}, \mathrm{T}}=\mathrm{P}_{\mathrm{F} / \mathrm{S}, \mathrm{T}} \cdot 1$ \\
\hline 2 & $\mathrm{~F} / \mathrm{M}$ & $\mathrm{R}_{\mathrm{FM}, \mathrm{T1}}=\mathrm{P}_{\mathrm{FM}, \mathrm{T1}} \cdot 2$ & $\mathrm{R}_{\mathrm{FM}, \mathrm{T2}}=\mathrm{P}_{\mathrm{FM}, \mathrm{T2}} \cdot 2$ & $\mathrm{R}_{\mathrm{F} M, \mathrm{T3}}=\mathrm{P}_{\mathrm{FM}, \mathrm{T3}} \cdot 2$ & $\mathrm{R}_{\mathrm{F} M \mathrm{M}, \mathrm{T4}}=\mathrm{P}_{\mathrm{FM}, \mathrm{T4}} \cdot 2$ \\
\hline 3 & $\mathrm{~F} / \mathrm{B}$ & $\mathrm{R}_{\mathrm{F} / \mathrm{B}, \mathrm{T1}}=\mathrm{P}_{\mathrm{FB}, \mathrm{T1}} \cdot 3$ & $\mathrm{R}_{\mathrm{FB}, \mathrm{T} 2}=\mathrm{P}_{\mathrm{FB}, \mathrm{T} 2} \cdot 3$ & $\mathrm{R}_{\mathrm{FB}, \mathrm{T3}}=\mathrm{P}_{\mathrm{FB}, \mathrm{T3}} \cdot 3$ & $\mathrm{R}_{\mathrm{FB}, \mathrm{T} 4}=\mathrm{P}_{\mathrm{FB}, \mathrm{T} 4} \cdot 3$ \\
\hline 4 & $\mathrm{~F} / \mathrm{VB}$ & $\mathrm{R}_{\mathrm{FNB}, T 1}=\mathrm{P}_{\mathrm{FNB}, \mathrm{T1}} \cdot 4$ & $\mathrm{R}_{\mathrm{FNB}, \mathrm{T2} 2}=\mathrm{P}_{\mathrm{FNB}, \mathrm{T2}} \cdot 4$ & $\mathrm{R}_{\mathrm{FNB}, T 3}=\mathrm{P}_{\mathrm{FNB}, \mathrm{T3}} \cdot 4$ & $\mathrm{R}_{\mathrm{FNB}, T 4}=\mathrm{P}_{\mathrm{FNB}, T 4} \cdot 4$ \\
\hline 1 & $\mathrm{LH} / \mathrm{S}$ & $\mathrm{R}_{\mathrm{LH} / \mathrm{S}, \mathrm{T1}}=\mathrm{P}_{\mathrm{LH} / \mathrm{T}, \mathrm{T1}} \cdot 1$ & $\mathrm{R}_{\mathrm{LHS}, \mathrm{T2}}=\mathrm{P}_{\mathrm{LHS}, \mathrm{T2}} \cdot 1$ & $\mathrm{R}_{\mathrm{LH} / \mathrm{T}, \mathrm{T3}}=\mathrm{P}_{\mathrm{LH} / \mathrm{T}, \mathrm{T3}} \cdot 1$ & $\mathrm{R}_{\mathrm{LH} / \mathrm{S}, T 4}=\mathrm{P}_{\mathrm{LH} / \mathrm{S}, T 4} \cdot 1$ \\
\hline 2 & $\mathrm{LH} / \mathrm{L}$ & $\mathrm{R}_{\mathrm{LH} M, \mathrm{T1}}=\mathrm{P}_{\mathrm{LH} M, \mathrm{~T} 1} \cdot 2$ & $\mathrm{R}_{\mathrm{LH} / \mathrm{M}, \mathrm{T2}}=\mathrm{P}_{\mathrm{LH} / \mathrm{M}, \mathrm{T2}} \cdot 2$ & $\mathrm{R}_{\mathrm{LHM}, \mathrm{T3}}=\mathrm{P}_{\mathrm{LHM}, \mathrm{T3}} \cdot 2$ & $\mathrm{R}_{\mathrm{LH} / \mathrm{M}, \mathrm{T} 4}=\mathrm{P}_{\mathrm{LH} / \mathrm{M}, \mathrm{T} 4} \cdot 2$ \\
\hline 3 & $\mathrm{LH} / \mathrm{M}$ & $\mathrm{R}_{\mathrm{LH} / \mathrm{T}, \mathrm{T1}}=\mathrm{P}_{\mathrm{LHB}, \mathrm{T1}} \cdot 3$ & $\mathrm{R}_{\mathrm{LH} /, T 2}=\mathrm{P}_{\mathrm{LH} /, T 2} \cdot 3$ & $\mathrm{R}_{\mathrm{LH} / \mathrm{B}, \mathrm{T3}}=\mathrm{P}_{\mathrm{LH} /, \mathrm{T3}} \cdot 3$ & $\mathrm{R}_{\mathrm{LH} /, T 4}=\mathrm{P}_{\mathrm{LH} / \mathrm{T}, \mathrm{T}} \cdot 3$ \\
\hline 4 & $\mathrm{LH} / \mathrm{B}$ & $\mathrm{R}_{\mathrm{LH} / \mathrm{B}, \mathrm{T} 1}=\mathrm{P}_{\mathrm{LH} / \mathrm{B}, \mathrm{T1}} \cdot 4$ & $\mathrm{R}_{\mathrm{LH} / \mathrm{BB}, \mathrm{T2}}=\mathrm{P}_{\mathrm{LH} / \mathrm{BB}, \mathrm{T2} 2} \cdot 4$ & $\mathrm{R}_{\mathrm{LHNB,T3}}=\mathrm{P}_{\mathrm{LHNB}, \mathrm{T3}} \cdot 4$ & $\mathrm{R}_{\mathrm{LH} / \mathrm{BB}, \mathrm{T4}}=\mathrm{P}_{\mathrm{LH} / \mathrm{BB}, \mathrm{T4}} \cdot 4$ \\
\hline 5 & $\mathrm{LH} / \mathrm{C}$ & $\mathrm{R}_{\mathrm{LH} / \mathrm{B}, T 1}=\mathrm{P}_{\mathrm{LH} / \mathrm{C}, \mathrm{T1}} \cdot 5$ & $\mathrm{R}_{\mathrm{LHNB}, T 2}=\mathrm{P}_{\mathrm{LH} / \mathrm{T}, \mathrm{T} 2} \cdot 5$ & $\mathrm{R}_{\mathrm{LH} / \mathrm{B}, \mathrm{T3}}=\mathrm{P}_{\mathrm{LH} / \mathrm{C}, \mathrm{T3}} \cdot 5$ & $\mathrm{R}_{\mathrm{LH} / \mathrm{B}, T 4}=\mathrm{P}_{\mathrm{LH} / \mathrm{C}, \mathrm{T4}} \cdot 5$ \\
\hline
\end{tabular}

requires the SFRS resources in strength of at least of 1 battalion (at least 480 firefighters).

Table 1 presents a statement of information about road events when the SFRS entities operated in 2019, [20].

Above-presented order highlights a possibility of use the database in risk assessment processes as direct numbers of events at particular levels of consequences are noticed. This increases a cognitive potential of the database and allows for its relatively easy use in road risk assessment method.

\subsection{Road risk assessment method}

At the highest level of generality, “(...) risk is the possibility of an event causing negative consequences (...)" [14]. Thus, a road risk $(R)$ can be named as a possibility of road events (collisions, accidents) causing negative consequences. From practical point of view, it can be expressed by a relation between the possibility measure $(P)$ and the consequence measure $(C)$, as it is presented in equation (1):

$R=P \cdot C$

Operationalizing the road risk assessment, particular kinds of measures depend on accessible information sources, which characterize the road safety in analyzed context. Due to SWD-ST database structure, $P$ is explicated by the events' frequency and $C$ considers classes of the consequences [22-23]. From this point, the database allows to elaborate a qualitative-quantitative road risk assessment method, in accordance with the following equation:

$R_{i, j}=P_{i, j} \cdot C_{i}$

where:

$R_{i, j}$ - road risk index for $i$-th class of consequences and $j$-th category of transportation mean,

$P_{i, j}$ - frequency of events in $i$-th class of consequences and $j$-th category of transportation mean,
$C_{i}$ - consequence measure which refers to $i$-th class of consequences.

Table 2 shows 36 detailed equations that describe different approaches for the road risk assessment, respecting events' categories ( $F$ and $L H$ ), multiple $C$ in particular events' categories, as well as different categories of transportation means. The table deals with elementary road risk index for $i$-th class of consequences and $j$-th category of the transportation means.

Equations from Table 2 make possible to implement data directly from the database and assess the road risk indexes. The total number of risk indexes, which are possible to be calculated from the elementary road risk assessment equations, is difficult to unambiguously estimate. However, respecting operational, resource allocation and training perspectives, for further analysis it is crucial to define:

- average road risk index for particular transportation means at particular classes of consequences:

$\overline{R_{i, j}}=\frac{\sum_{m=1}^{n} R_{i, j, m}}{m}$

where: $m=\{2015,2016,2017,2018,2019\}$ in analyzed period of time,

- total road risk index for particular transportation means (in terms of all the classes of consequences) in analyzed year:

$R_{\text {total }}=\sum_{i} \sum_{j} R_{i, j}$

- cumulated road risk index covering all transportation means (in terms of all classes of consequences) in analyzed year

$R_{\text {cum }}=\sum_{j} R_{\text {total }}$.

Presented road risk assessment method allows to create the road safety picture due to the most serious events on Polish roads. This gives an additional value for further analysis on operational means connected to the non-system and system dimensions of the SFRS interventions. 


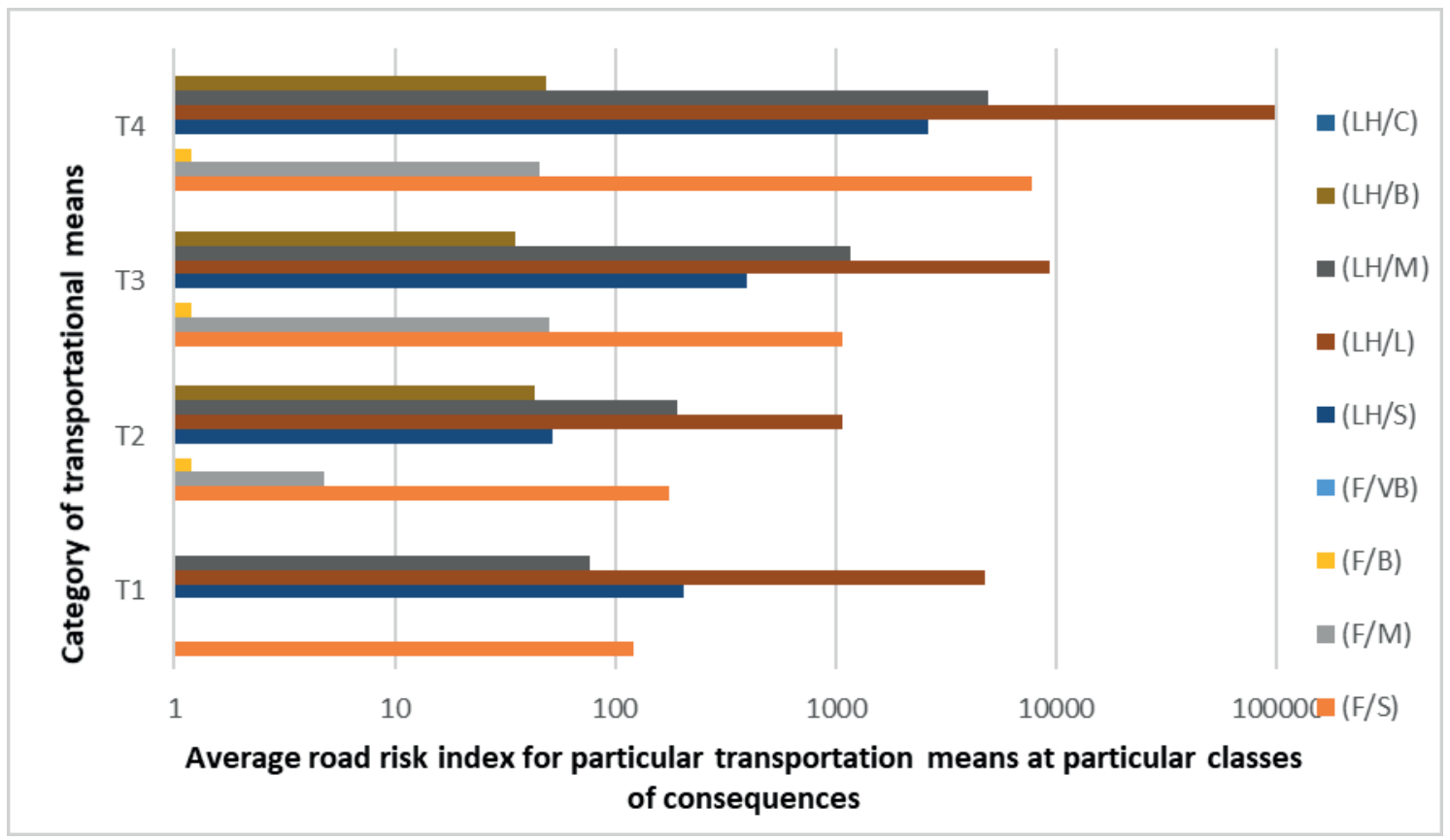

Figure 1 Average road risk index for particular transportation means at particular classes of consequences $\left(\overline{R_{i, j}}\right)$

\section{Results and Discussion}

\subsection{Road risk assessment and non-system dimension of the SFRS interventions}

As the non-system dimension of the SFRS interventions patterns the micro scale of road risk assessment, the assessment results can be interesting for the fire rescue unit commanders, local SFS headquarters and local administration decision makers (mayors, starosts).

Use of Equation (2) gives elementary results of road risk assessment that are compiled in Annex 1 to this paper. In addition, practical implementation of Equation (3) allows to visualize differences in average risk indexes for particular transportation means at particular levels of consequences. They are presented in Figure 1.

Referring to particular classes of consequences is useful from practitioners' point of view, as it reflects total spectrum of road events characteristics (initiating factors, hazard development and firefighting rescue action effectiveness). Preliminary analysis of Figure 1 shows that the highest levels of the road risk concern LH/L and F/S events for T4 (cars, light traffic machines and car trailers), as well as LH/L events for T3 (lorries, heavy traffic machines, tanks and lorry trailers) and T1 (motorcycles and bikes). Relevant indexes cover approximately 90\% of the total average road risk index value. Thus, the $\mathrm{LH} / \mathrm{L}$ and $\mathrm{F} / \mathrm{S}$ should have the strongest influence on operational procedures, tactics and strategies directed on technical (corresponding to LH specification) cooperation with medical rescue teams, other fire service teams (totally 15-72 rescuers) and 1 special rescue unit participation in the action. Consequently, such a perspective should be used when training scenarios are formulated. Relatively small number of victims is noticed, so the main attention should be put to strictly technical activities. Especially when the medical support is assumed. Quite interesting are results for average risk indexes for fires. Only one distinctive value is noticed for $\mathrm{F} / \mathrm{S}$. This proves that firefighting protection for the road event should be generally ensured at the basic scope (1-2 engines to build maximum 4 extinguishing jets). Previous conclusions shed a light into resources allocation. As firefighting protection resources means mostly 1-2 engines with 6-8 firemen, the rest of human resources and equipment need to be technically-related. This can be dealt with as a suggestion for the road emergency standard, as well.

Certainly, other kinds of circumstances should be also mentioned when operational, resources location and training issues are analyzed. Nevertheless, the results highlight main, risk-based determinants of the issues beyond doubt. Rationally, determination of information about other classes of consequences and categories of transportation means should be limited to additional training scenarios, continuity operational plans and resources allocation for the special rescue unit for road emergencies.

\subsection{Road risk assessment and system dimension of the SFRS interventions}

System dimension of the SFRS interventions respects the macro scale of the road risk assessment. Thus, relevant results should give a valuable information for prime commanders of the SFS (main headquarters, province headquarters) and decision makers at a strategic level of public administration (ministers, head of the central entities).

Figure 2 presents values of cumulated road risk index for particular transportation means in terms of all the types 


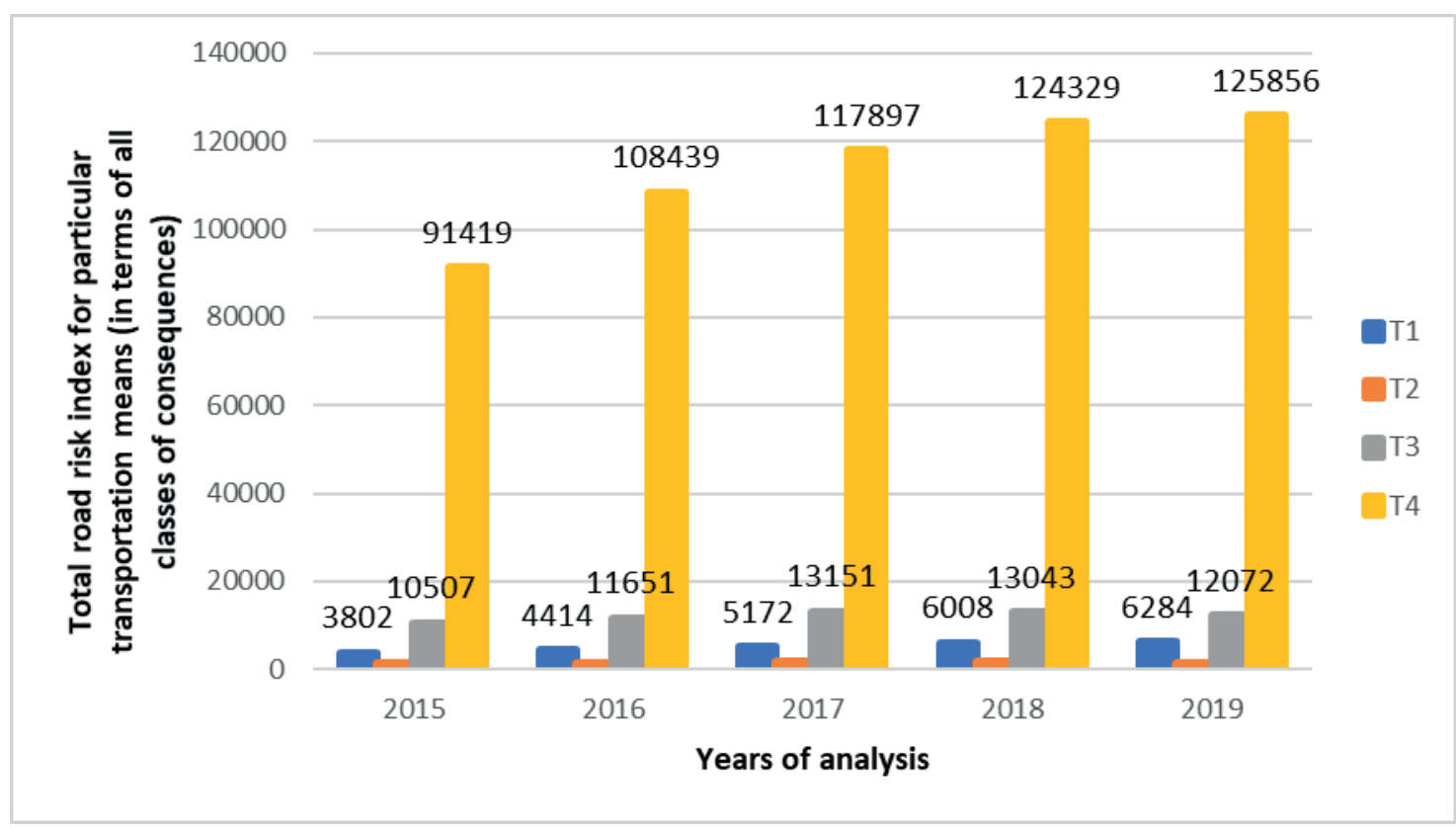

Figure 2 Total road risk index for particular transportation means (in terms of all the classes of consequences) in analyzed year.

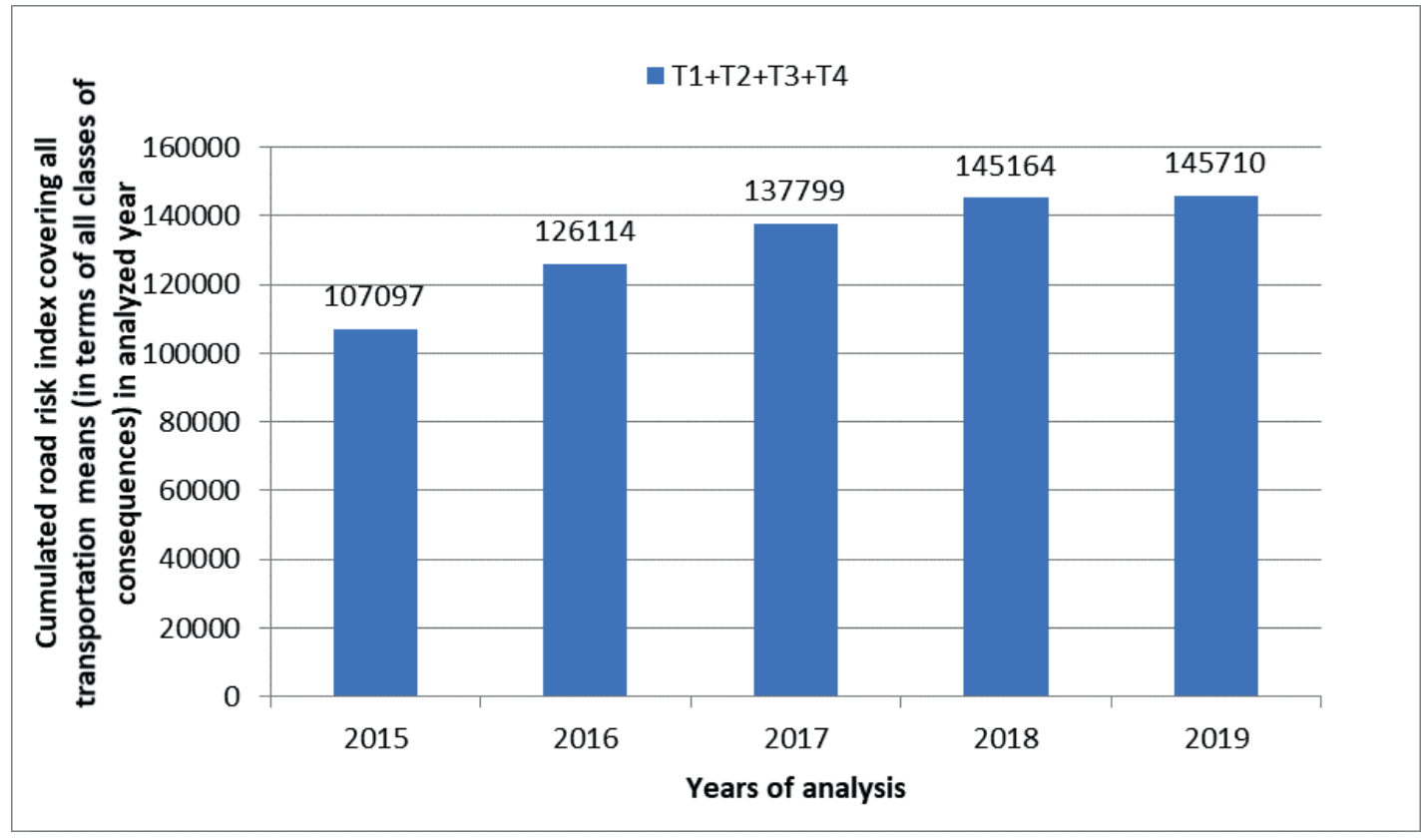

Figure 3 Cumulated road risk index covering all the transportation means (in terms of all the classes of consequences) in analyzed year

of events for the last five years in Poland. The time-related distribution of values shows crucial points for macro scale analysis.

Analysis of the total road risk index in terms of all the classes of consequences in particular years gives information indicating general road safety situation in Poland, where T1 - motorcycles, bikes, T2 - buses, trolley buses, T3 - lorries, heavy traffic machines, tanks, lorry trailers and T4 - cars, light traffic machines, car trailers. The results confirm a core location of the T4 values in an entire road risk picture. The total road risk index for cars, light traffic machines and car trailers clearly exceeds other indexes. It emphasizes that object circumstances should be taken into account in emergency system design above all. In this way, additional emergency units may be investigated to build new system development opportunities in the nearest future (new institutional and non-institutional partners). Furthermore, the system needs to be prepared especially for the T4 event conditions on a mass scale of the events occurrence (many accidents at the same time in the same administration zone). Information concerning rescue from cars, light traffic machines and car trailers should be an element of current, emergency state-of-the-art, widely implemented in all the fire service units. Object procedures should be thoroughly exercised and state a training framework for all the road emergency scenarios. In addition, 
central-planned equipment procurements need to stem from the highest road risk level in described context. Respecting the micro scale analysis, the procurements and the system development direction should ensure a relatively quick build of potential for the riskiest events (they must ensure that the first echelon of emergency resources will meet the $\mathrm{LH} / \mathrm{L}$ and $\mathrm{F} / \mathrm{S}$ requirements).

Knowledge of the total road risk index for particular transportation means (in terms of all the classes of consequences) in analyzed year enables to calculate cumulated road risk index covering all the transportation means (in terms of all classes of consequences) in this year - to calculate it, total road risk values obtained in each year for particular category of transport means should be summed.

Figure 3 indicates a steady increase in value in each sequential year for all the categories of transportation means (where T1 - motorcycles, bikes, T2 - buses, trolley buses, T3 - lorries, heavy traffic machines, tanks, lorry trailers and T4 - cars, light traffic machines, car trailers). However, a significant difference should be noted. The increase in the value of risk in a given year in relation to the value of risk from the previous year, expressed as a percentage differed significantly in subsequent years and amounted to:

- $\quad$ in $2016-17.76 \%$ (compared to 2015);

- $\quad$ in $2017-9.27 \%$ (compared to 2016);

- $\quad$ in $2018-5.34 \%$ (compared to 2017);

- $\quad$ in $2019-0.38 \%$ (compared to 2018).

This means that cumulated road risk index covering all transportation means (in terms of all the classes of consequences) permanently increases and expresses a decrease of road safety in Poland.

\section{Conclusion}

Risk assessment can be executed in many ways. Generally, it is a derivative of a simple correlation between probability and consequences. Practically, it requires access to realistic data. Especially, when the qualitativequantitative or quantitative methods are desired.

The road risk assessment definitely requires a strong relation to real data, giving realistic reasons for decision makers to create operational procedures, resource allocation and training processes, referring to micro scale and macro scale of an analysis.

Even if the results do not surprise (T4 seems to be quite typical group of vehicles which participate in collisions and road accidents, in general), the methodology of the road risk assessment states framework for detailed analysis of the road risk determinants and their hazards-, type of consequences- and time-related divisions. The natural next step seems to be the risk mapping, which makes possible to analyze road risks in particular administration zones with deepen research of relevant differences and reasons. Moreover, different groups of transportation means can be scientifically explored (rail, inland etc.). In addition, the road risk assessment is based on direct number of road incidents. It is justified by the research objective, when operational perspective of the fire service states the research framework. For the fire service point of view, it is crucial to be aware of the number of events and their operational consequences (thus relation to number of extinguishing jets, area or volume of hazard, number of victims, number of rescuers, support from other emergency entities etc.). Classes of consequences in the SFS data base match these issue. Thus, the data base allows for the risk assessment in its emergency operational realm. However, in the future research additional risk measures can be considered. Respecting number of vehicles, number of drivers, number of vehicle kilometers per year would increase the risk assessment potentials for other road safety perspectives and make closer to its objective value.

Concluding, the total picture of the road safety is very complex and determined by many different factors. Presented method makes a first step to do this with focus on events with the highest influence on safety, when emergency services are involved to rescue peoples' lives and health.

\section{References}

[1] LAKKA, K., STACHOVA, D., KAMPOVA, K. Assessment of the mobile risk source in road transport. Communications - Scientific Letters of the University of Zilina [online]. 2019, 21(1), p. 68-73 [accessed 2020-02-28]. ISSN 2585-7878, eISSN 2585-7878. Available from: http://komunikacie.uniza.sk/index.php/communications/article/view/1169/1133

[2] LUSKOVA, M., TITKO, M., O'CONNOR, A. Societal vulnerability impacts of extreme weather events on land transport infrastructure. Communications - Scientific Letters of the University of Zilina [online]. 2018, 20(2), p. $62-67$ [accessed: 2020-02-28]. ISSN 2585-7878, eISSN 2585-7878. Available from: http://komunikacie.uniza.sk/index.php/communications/ article/view/89/70

[3] Mobility and transport. Road safety - European Commission [online] [accessed 2020-02-28]. Available from: https:// ec.europa.eu/transport/road_safety/index_en

[4] DINH, D. D., VU, N. H., MCILROY, R. C., PLANT, K. A., STANTON, N. A. Effects of attitudes towards traffic safety and risk perceptions on pedestrian behaviour in Vietnam. IATSS Research [online]. 2020, in press [accessed 2020-02-28]. ISSN 0386-1112. Available from: https://doi.org/10.1016/j.iatssr.2020.01.002 
[5] HARRIS, S. The real number of road traffic accident casualties in the Netherlands: A year-long survey. Accident Analysis and Prevention [online]. 1990, 22(4), p. 371-378 [accessed 2020-02-28]. ISSN 0001-4575. Available from: https://doi.org/10.1016/0001-4575(90)90052-M

[6] ZWEGLINSKI, T., GROMEK, P., PREDECKA, A., GIKIEWICZ, M. Awareness raising, bridging and building community resilience. 1 ed. Warsaw-Karlstad: Warsaw-Publishing House of the Main School of Fire Service, 2015. ISBN 9788388446641.

[7] VORKO-JOVIC, A., KERN, J., BILOGLAV, Z. Risk factors in urban road traffic accidents. Journal of Safety Research [online]. 2006, 37 [accessed 2020-02-28]. ISSN 0022-4375. Available from: https://doi.org/10.1016/j.jsr.2005.08.009

[8] YOSHOKATE, H., SHINO, M. Risk assessment based on driving behaviour for preventing collisions with pedestrians when making across-traffic turns at intersections. IATSS [online]. 2018, 42, p. 240-247 [accessed 2020-02-28]. ISSN 03861112. Available from: https://doi.org/10.1016/j.iatssr.2018.02.001

[9] SALONEN, A. O. Passenger's subjective traffic safety in-vehicle security and emergency management in the driverless shuttle bus in Finland. Transport Policy [online]. 2018, 61, p. 106-110 [accessed 2020-02-28]. ISSN 0967-070X. Available from: https://doi.org/10.1016/j.tranpol.2017.10.011

[10] AYGENCEL, G., KARAMERCAN, M., ERGIN, M., TELATAR, G. Review of traffic accident cases presenting to an adult emergency service in Turkey. Journal of Forensic and Legal Medicine [online]. 2008, 15 [accessed 2020-02-28]. ISSN 1752-928X. Available from: https://doi.org/10.1016/j.jflm.2007.05.005

[11] GAN, CH., JUNDE, C., WEI, H., JIANHUA, G. Optimized traffic emergency resource scheduling using time varying rescue route travel time. Neurocomputing [online]. 2018, 275, p. 1567-1575 [accessed 2020-02-28]. ISSN 0925-2312. Available from: https://doi.org/10.1016/j.neucom.2017.09.086

[12] HUANG, D., CHU, X., MAO, Z. A Simulation framework for emergency response of highway traffic accident [online]. Procedia Engineering [online]. 2012, 29, p. 1075-1080 [accessed 2020-02-28]. ISSN 1877-7058. Available from: https:// doi.org/10.1016/j.proeng.2012.01.092

[13] HOLLA, K. Dealing with key terms in risk analysis and phenomenon of uncertainty in this process. Communications Scientific Letters of the University of Zilina [online]. 2007, 9(4), p. 59-61 [accessed 2020-02-28]. ISSN 2585-7878, eISSN 2585-7878. Available from: http://komunikacie.uniza.sk/index.php/communications/article/view/1157

[14] WOLANIN, J. Common societal security culture in the Baltic Sea Region: basics and the way forward [online]. 1 ed. Stockholm: Council of the Baltic Sea States (CBSS) Secretariat, 2017 [accessed 2020-02-28]. Available from: http://www. bsr-secure.eu/wp-content/uploads/2017/03/Common-Societal-Security-Culture-working-paper.pdf

[15] SIMAK, L., HOLLA, K., RISTVEJ, J. Crisis management in public administration. Crisis management I. Theory of crisis management. 1 ed. Zilina: University of Zilina Publishing House, 2013. ISBN 9788055406510.

[16] GROMEK, P. Cooperation framework for radiological rescue operations. In: Safety in nuclear energetics. 1. Ed. Warsaw: Warsaw: Publishing House of The Main School of Fire Service, 2017, p. 313-323. ISBN 978-83-88446-93-1.

[17] GROMEK, P. ADR safety system in efficiency conditioning. Procedia Engineering [online]. 2017, 192, p. 271-271 [accessed 2020-05-08]. ISSN 1877-7058. Available from: https://doi.org/10.1016/j.proeng.2017.06.047

[18] Report on realization of the Program for Rescue and Civil Protection in 2014-2020 [online] [accessed 2020-05-08]. Available from: https://www.gov.pl/web/mswia/program-ratownictwa-i-ochrony-ludnosci-na-lata-2014-2020

[19] Executory Law of Ministry of Interior and Public Administration 4 July 2017 on particular organization of national firefighting rescue system (Dz. U. 2017 item 1319).

[20] Information about emergency interventions of SFRS entities - The Main Headquarters of SFS [online] [accessed 202002-25]. Available from: https://www.straz.gov.pl/panstwowa_straz_pozarna/interwencje_psp

[21] Guidelines for incidents' records in Decision Support System of SFS. 2019.

[22] KOZIOL, J., GROMEK, P. Creating safety in transport - traffic risk approach. Procedia Engineering [online]. 2017, 192, p. 457-462 [accessed 2020-03-01]. ISSN 1877-7058. Available from: https://doi.org/10.1016/j.proeng.2017.06.079

[23] GHALEH, S., OMIDVARI, M., NASSIRI, P., MOMENI, M., MOHAMMADREZA, S., LAVASANI, M. Pattern of safety risk assessment in road fleet transportation of hazardous materials (oil materials). Safety Science [online]. 2019, 116, p. 1-12 [accessed 2020-03-09]. ISSN 0925-7535. Available from: https://doi.org/10.1016/j.ssci.2019.02.039 


\section{Annex}

Table 3 Results of the elementary road risk assessment for T1 (motorcycles, bikes), [20]

\begin{tabular}{cccccc}
\hline \multirow{2}{*}{$\begin{array}{c}\text { Category of } \\
\text { consequences }(i)\end{array}$} & 2015 & 2016 & 2017 & 2018 & 2019 \\
\cline { 2 - 5 } F/S & 105 & 109 & 112 & 146 & 132 \\
F/M & 0 & 0 & 2 & 0 & 2 \\
F/B & 0 & 0 & 0 & 0 & 0 \\
F/VB & 0 & 0 & 0 & 0 & 204 \\
LH/S & 181 & 180 & 209 & 5522 & 5796 \\
LH/L & 3470 & 4174 & 5198 & 0 \\
LH/M & 42 & 60 & 0 & 0 & 0 \\
LH/B & 4 & 0 & 0 & 0 & 0 \\
LH/C & 0 & 0 & & & 150 \\
\hline
\end{tabular}

Table 4 Results of the elementary road risk assessment for T2 (buses, trolley buses), [20]

\begin{tabular}{|c|c|c|c|c|c|}
\hline \multirow{2}{*}{$\begin{array}{c}\text { Category of } \\
\text { consequences }(i)\end{array}$} & \multicolumn{4}{|c|}{ Year } & \multirow[b]{2}{*}{2019} \\
\hline & 2015 & 2016 & 2017 & 2018 & \\
\hline $\mathrm{F} / \mathrm{S}$ & 176 & 165 & 174 & 176 & 185 \\
\hline $\mathrm{F} / \mathrm{M}$ & 2 & 0 & 6 & 10 & 6 \\
\hline $\mathrm{F} / \mathrm{B}$ & 3 & 0 & 0 & 0 & 3 \\
\hline $\mathrm{F} / \mathrm{VB}$ & 0 & 0 & 0 & 0 & 0 \\
\hline $\mathrm{LH} / \mathrm{S}$ & 43 & 42 & 59 & 61 & 57 \\
\hline $\mathrm{LH} / \mathrm{L}$ & 932 & 1056 & 1106 & 1276 & 1014 \\
\hline LH/M & 165 & 198 & 198 & 201 & 201 \\
\hline $\mathrm{LH} / \mathrm{B}$ & 48 & 40 & 36 & 60 & 32 \\
\hline $\mathrm{LH} / \mathrm{C}$ & 0 & 0 & 0 & 0 & 0 \\
\hline
\end{tabular}

Table 5 Results of the elementary road risk assessment for T3 (lorries, heavy traffic machines, tanks, lorry trailers), [20]

\begin{tabular}{cccccc}
\hline \multirow{2}{*}{$\begin{array}{c}\text { Category of } \\
\text { consequences }(i)\end{array}$} & 2015 & 2016 & 2017 & 2018 & 2019 \\
\cline { 2 - 6 } & 1038 & 1031 & 1069 & 1151 & 1091 \\
F/S & 54 & 54 & 36 & 56 & 50 \\
F/M & 0 & 0 & 0 & 6 & 0 \\
F/B & 0 & 0 & 0 & 0 & 393 \\
F/VB & 333 & 361 & 433 & 9960 & 9014 \\
LH/S & 8244 & 9276 & 10320 & 1362 & 1512 \\
LH/L & 810 & 897 & 48 & 56 & 12 \\
LH/M & 28 & 32 & 0 & 0 & 0 \\
LH/B & 0 & 0 & & & \\
LH/C & & & 1245 & & \\
\hline
\end{tabular}


Table 6 Results of the elementary road risk assessment for T4 (cars, light traffic machines, car trailers), [20]

\begin{tabular}{|c|c|c|c|c|c|}
\hline \multirow{2}{*}{$\begin{array}{c}\text { Category of } \\
\text { consequences }(i)\end{array}$} & \multicolumn{4}{|c|}{ Year } & \multirow[b]{2}{*}{2019} \\
\hline & 2015 & 2016 & 2017 & 2018 & \\
\hline $\mathrm{F} / \mathrm{S}$ & 6948 & 7511 & 7888 & 8479 & 8306 \\
\hline $\mathrm{F} / \mathrm{M}$ & 64 & 28 & 30 & 40 & 64 \\
\hline $\mathrm{F} / \mathrm{B}$ & 0 & 0 & 3 & 3 & 0 \\
\hline $\mathrm{F} / \mathrm{VB}$ & 0 & 0 & 0 & 0 & 0 \\
\hline $\mathrm{LH} / \mathrm{S}$ & 2310 & 2353 & 2777 & 2915 & 2806 \\
\hline $\mathrm{LH} / \mathrm{L}$ & 78700 & 94434 & 102286 & 107384 & 107884 \\
\hline LH/M & 3345 & 4077 & 4833 & 5472 & 6756 \\
\hline LH/B & 52 & 36 & 80 & 36 & 40 \\
\hline $\mathrm{LH} / \mathrm{C}$ & 0 & 0 & 0 & 0 & 0 \\
\hline
\end{tabular}

